\title{
CONHECIMENTOS E PRÁTICAS DE ESPORTE DE ESTUDANTES DO ENSINO MÉDIO DAS REGIONAIS DO ESTADO DO ACRE
}

Recebido em: $17 / 11 / 2020$

Aprovado em: 29/06/2021

Licença:@) (1) @

Eliane Elicker

Adriane Corrêa da Silva

Universidade Federal do Acre (UFAC)

Rio Branco - AC - Brasil

Cledir de Araújo Amaral

Instituto Federal de Educação, Ciência e Tecnologia do Acre (IFAC)

Rio Branco - AC - Brasil

Oyatagan Levy Pimenta da Silva

Centro Universitário Meta (UNIMETA)

Rio Branco - AC - Brasil

Tiago Barbosa do Nascimento

Rede Estadual de Ensino de Rio Branco

Rio Branco - AC - Brasil

Alessandra Lima Peres de Oliveira

Eroína Moreira de Melo

Carlos Roberto Teixeira Ferreira

Universidade Federal do Acre (UFAC)

Rio Branco - AC - Brasil

Vitor Gomes Felisberto da Costa

Governo do Estado do Acre

Rio Branco - AC - Brasil

Sandro Victor Alves Melo

Yves Benevides Feitoza

Mauro José de Deus Moraes

Universidade Federal do Acre (UFAC)

Rio Branco - AC - Brasil

RESUMO: Este estudo visa descrever os conhecimentos e práticas de esporte de estudantes do ensino médio. A problematização baseia-se em como estão sendo percebidas essas práticas e os conhecimentos esportivos dos estudantes das instituições federais do Acre. É um estudo transversal do tipo descritivo e exploratório, com utilização de questionário estruturado, validado por um painel de especialistas. Os respondentes do estudo foram 674 estudantes. Os resultados apontam que os participantes reconhecem a importância do esporte para a melhoria de vários aspectos 
de sua vida, no entanto, uma grande parcela não realiza atividades esportivas nos horários de folga. O principal motivo referenciado para não praticar esporte fora da escola foi a falta de tempo. Entre os que praticam esporte no tempo livre, os motivos foram a melhora no desempenho físico e ser um hábito saudável, e as modalidades mais praticadas são o futebol e o futsal.

PALAVRAS-CHAVE: Conhecimento-Esporte. Práticas de Esporte. Ensino Médio. Esportes.

\section{SPORTS KNOWLEDGE AND PRACTICES OF HIGH SCHOOL STUDENTS IN THE REGIONS OF THE STATE OF ACRE}

ABSTRACT: This study aims to describe the knowledge and sports practices of high school students. The problematization is based on how these practices and the sports knowledge of students from federal institutions in Acre are being perceived. It is a cross-sectional study of a descriptive and exploratory type, using a structured questionnaire, validated by a panel of experts. Study respondents were 674 students. The results show that the participants recognize the importance of sport for the improvement of various aspects of their lives, however, a large portion does not perform sports activities during their free time. The main reason cited for not playing sports outside school was the lack of time. Among those who practice sports in their free time, the reasons were the improvement in physical performance and being a healthy habit, and the most practiced modalities are football and futsal.

KEYWORDS: Knowledge-Sport. Sport Practices. High School. Sports.

\section{Introdução}

No campo acadêmico e científico muito se tem discutido sobre o esporte e suas implicações no meio social, da participação das classes sociais em diferentes contextos e formas de manifestações do fenômeno esportivo.

O esporte, segundo Stigger (2002), pode ser compreendido como práticas regulamentadas que se relacionam com as organizações externas, de acordo com a subjetividade dos sujeitos envolvidos no processo.

Há muitas definições, principalmente no senso comum, que compreendem o fenômeno esporte como atividade física. Em outras palavras, ele envolve o uso de atividades motoras, proeza física ou esforço físico. Significa dizer que toda prática 
Conhecimentos e Práticas de Esporte de Estudantes do Ensino Médio das Regionais do Estado do Acre

Eliane Elicker, Adriane C. da Silva, Cledir de A. Amaral, Oyatagan L. P. da Silva, Tiago B. do

Nascimento, Alessandra L. P. de Oliveira, Eroína M. de Melo, Carlos Roberto T. Ferreira, Vitor G. F. da Costa, Sandro Victor A. Melo, Yves B. Feitoza e Mauro José de D. Moraes

esportiva é uma atividade física, mas nem toda atividade física é esporte, pois, para ser classificada assim, ela deve ocorrer sob um conjunto particular de circunstâncias (BARBANTI, 2011).

Na obra Estudos do lazer: uma introdução, é abordado que o esporte, além das outras práticas, é uma atividade de lazer, uma vez que o sujeito pratica em seu tempo livre e o toma como uma atividade prazerosa (MARCELLINO, 1996).

O esporte é evidenciado e aceito como um dos fenômenos socioculturais e políticos mais importantes nessa transição de séculos por sua influência social e por estar inserido desde as práticas livres até as educacionais e profissionais. Os significados do esporte têm uma variabilidade desde a sua origem até os tempos atuais, recebendo diferentes sentidos, de acordo com o momento, o ambiente e o indivíduo que o pratica (TUBINO, 2010).

O conceito de esporte no Brasil está atualizado com a evolução conceitual do fenômeno sociocultural esportivo, ao aceitá-lo como direito de todas as pessoas, e com as formas de exercício desse direito — esporte-educação, esporte-lazer e esporteperformance/desempenho (TUBINO, 2010). De acordo com o autor, é possível apreender a grandiosidade do fenômeno esportivo na sociedade contemporânea, uma vez que é um elemento cultural que traz consigo uma bagagem de conhecimentos e valores, que implicam diretamente na formação do cidadão a partir das vivências que lhe são oportunizadas.

Com a promulgação da Constituição Federal de 1988, por meio do artigo $6^{\circ}$, o esporte e o lazer começaram a ser reconhecidos como direito social e dever do Estado. Desde então, o esporte e o lazer têm sido foco de estudos e produções que corroboram a necessidade de políticas públicas sociais que garantam a apropriação dessas práticas sociais (SOARES, 2017). 
Conhecimentos e Práticas de Esporte de Estudantes do Ensino Médio das Regionais do Estado do Acre

Eliane Elicker, Adriane C. da Silva, Cledir de A. Amaral, Oyatagan L. P. da Silva, Tiago B. do

Nascimento, Alessandra L. P. de Oliveira, Eroína M. de Melo, Carlos Roberto T. Ferreira, Vitor G. F. da Costa, Sandro Victor A. Melo, Yves B. Feitoza e Mauro José de D. Moraes

Pesquisas também localizam o fenômeno esportivo no "âmbito das necessidades intermediárias, como um dos instrumentos necessários à concretização dos direitos de cidadania”. Nesse sentido, espera-se pelo protagonismo do Estado (ATHAYDE et al., 2016, p. 495).

Ao aproximarem-se da discussão sobre a concretude das políticas públicas de esporte e lazer como direito social, Pintos et al. (2016) entendem que a política pública deve priorizar as necessidades sociais e garantir os princípios de igualdade, equidade e justiça social.

Ainda nos referindo sobre o esporte, quanto aos conhecimentos e práticas esportivas, entendemos que os espaços mais adequados para a discussão sobre o esporte, estão nas disciplinas dos cursos de formação em educação física e na educação física escolar. Isso, porque esses são ambientes estruturados e seriam alternativas ideais para a discussão sobre os direitos de acesso ao esporte, no sentido de que fossem mobilizados esses repertórios culturais junto à população (BRASIL, 1988; RAMOS; ISAYAMA, 2009).

Os conhecimentos esportivos afloram de saberes específicos, de acordo com competências, conteúdos, habilidades e objetivos, produzidos, com base nas experiências corporais. Quando relativos às práticas sistematizadas conceitualmente, no caso do futebol de sete, esses saberes ficam vinculados ao saber praticar, saber fazer e saber conhecer (conhecimentos técnicos e críticos), e ao serem potencializados num contexto de diferenças, existente no ambiente escolar, o esporte ganha visibilidade e poderá ser melhor compreendido como fenômeno cultural e não naturalmente, como conteúdo da educação física escolar. Diante dessa exposição, o esporte é assimilado como realidade cultural e social de forma dinâmica e provisória (CARLAN; KUNZ; FENSTERSEIFER, 2012). 
Conhecimentos e Práticas de Esporte de Estudantes do Ensino Médio das Regionais do Estado do Acre

Eliane Elicker, Adriane C. da Silva, Cledir de A. Amaral, Oyatagan L. P. da Silva, Tiago B. do

Nascimento, Alessandra L. P. de Oliveira, Eroína M. de Melo, Carlos Roberto T. Ferreira, Vitor G. F. da Costa, Sandro Victor A. Melo, Yves B. Feitoza e Mauro José de D. Moraes

Nessa perspectiva, percebemos que existe ainda uma necessidade emergente de ampliar as pesquisas sobre as dimensões do esporte e os respectivos conhecimentos, adotando referências que tematizem e mobilizem o fenômeno esportivo e suas perspectivas teórico-metodológicas (EUZÉBIO; ORTIGARA, 2011).

Diante do exposto, a problematização deste artigo baseia-se em como estão sendo percebidas as práticas e os conhecimentos esportivos, pelos estudantes do ensino médio das regionais do estado do Acre, realizado a partir dos dados da pesquisa "Diagnóstico do Esporte e do Lazer no Estado do Acre". Para isso, o objetivo do presente trabalho é descrever os conhecimentos e práticas de esporte encontradas a partir desse diagnóstico.

\section{Método}

Trata-se de um estudo transversal do tipo descritivo e exploratório, sendo os dados da pesquisa obtidos por meio do "Diagnóstico do Esporte e do Lazer no Estado do Acre", uma pesquisa realizada pela Rede Cedes Acre com estudantes do ensino médio das instituições federais de ensino situadas nos municípios-sede de cada regional do estado no ano 2019.

Foram considerados como população de base 1.175 estudantes do ensino médio, matriculados em 2019 no Colégio de Aplicação (CAP) da Universidade Federal do Acre (Ufac), situado no município de Rio Branco, regional Baixo Acre; bem como os alunos do ensino médio integrados ao curso técnico do Instituto Federal de Educação, Ciência e Tecnologia do Acre (Ifac), campus Xapuri, regional Alto Acre; campus Sena Madureira, regional Purus; campus Tarauacá, regional Tarauacá/Envira; campus Cruzeiro do Sul, regional Juruá.

Participaram da pesquisa 674 estudantes do ensino médio das instituições federais situadas nas cinco regionais do estado, o que corresponde a 57\% da população 
Conhecimentos e Práticas de Esporte de Estudantes do Ensino Médio das Regionais do Estado do Acre

Eliane Elicker, Adriane C. da Silva, Cledir de A. Amaral, Oyatagan L. P. da Silva, Tiago B. do

Nascimento, Alessandra L. P. de Oliveira, Eroína M. de Melo, Carlos Roberto T. Ferreira, Vitor G. F. da Costa, Sandro Victor A. Melo, Yves B. Feitoza e Mauro José de D. Moraes

elegível.

Os participantes responderam um questionário estruturado em módulos temáticos, composto por questões abertas e fechadas, o qual foi construído e validado pela equipe de pesquisadores da Rede Cedes Acre. Para o presente estudo foram utilizados os dados referentes ao módulo II do formulário que trata dos conhecimentos e práticas do esporte. Especificamente, as questões retrataram as definições e a importância do esporte, sobre a prática de esporte atual e em algum momento da vida, além da frequência e da prática de esportes nas aulas de educação física.

Em cada unidade de ensino (CAP/Ufac ou nos campi do Ifac), os estudantes, previamente mobilizados para participar do estudo, foram dispostos numa sala de aula onde receberam as orientações e esclarecimentos necessários sobre o questionário impresso, o qual foi preenchido pelos alunos sob a supervisão de dois pesquisadores.

Os dados foram tabulados e digitados numa planilha preparada no programa Microsoft Office Excel® e, posteriormente, analisados no pacote estatístico Statistical Package for the Social Sciences® (SPSS, versão 22.0). Os resultados foram expressos com técnica de estatística descritiva por meio de distribuição de frequências relativa e absoluta, bem como por meio de média das variáveis de interesse.

A pesquisa foi aprovada pelo Comitê de Ética e Pesquisa da Universidade Federal do Acre (CEP/ UFAC) sob o parecer $n^{\circ}$ 3.777.903, CAAE $n^{\circ}$. 19327819.0.0000.5010, e todos os participantes assinaram o Termo de Consentimento Livre e Esclarecido (TCLE) e nos casos de menores de idade os responsáveis legais assinaram um Termo de Anuência Livre e Esclarecido (TALE).

\section{Resultados}

Dentre os 674 estudantes, 35,6\% eram alunos do primeiro ano, 37,7\% do segundo, $18,5 \%$ do terceiro e $8,2 \%$ do quarto ano. 
Conhecimentos e Práticas de Esporte de Estudantes do Ensino Médio das Regionais do Estado do Acre

Eliane Elicker, Adriane C. da Silva, Cledir de A. Amaral, Oyatagan L. P. da Silva, Tiago B. do Nascimento, Alessandra L. P. de Oliveira, Eroína M. de Melo, Carlos Roberto T. Ferreira, Vitor G. F. da Costa, Sandro Victor A. Melo, Yves B. Feitoza e Mauro José de D. Moraes

Sobre a frequência de alunos no quarto ano, cabe destacar que o Ifac oferta o ensino técnico integrado ao ensino médio, no qual o estudante tem a formação propedêutica integrada à formação técnica. Inicialmente os cursos técnicos integrados do Ifac foram dimensionados para quatro anos, em virtude da extensa carga horária da formação técnica e básica, porém com as revisões dos Projetos Pedagógicos de Curso, esses cursos passaram a ter somente três anos, mas com aulas regulares em dois turnos. A baixa frequência de alunos nas turmas do quarto ano se justifica em virtude de que 2019 foi o último ano dos cursos com formato de quatro anos nos Campi do Ifac.

O grupo de estudantes caracterizou-se pelo predomínio do sexo feminino, $51,1 \%$, pretos e pardos corresponderam a $81 \%$, com média de idade de 16 anos. O local de residência na zona urbana foi referido por $81,6 \%$, onde conviviam em média com 4,2 pessoas no domicílio, sendo $85,4 \%$ dos estudantes não tinham participação na composição da renda familiar. Quanto à idade de início da prática esportiva a média foi de 9 anos, tanto para os meninos quanto para as meninas.

Em relação aos conceitos sobre as três formas de manifestações do fenômeno esportivo, 59,2\% dos alunos indicaram o conceito e os exemplos relacionados ao esporte-participação como atividades que para eles representam os esportes, seguido pelos indicativos do esporte-rendimento $49,2 \%$, enquanto que $26,7 \%$ indicaram o conceito e os exemplos do esporte-educacional como representante do esporte. Vale destacar que eles poderiam indicar mais de uma opção (TABELA 1).

Quanto à importância que os estudantes atribuem ao esporte, em vários aspectos de sua vida, ficou evidente que a maioria considera o esporte muito importante ou importante, com destaque para o aspecto saúde e equilíbrio do estresse. Vale destacar que a metade dos estudantes assinalaram que o esporte pode contribuir com o rendimento escolar. 
Conhecimentos e Práticas de Esporte de Estudantes do Ensino Médio das Regionais do Estado do Acre Eliane Elicker, Adriane C. da Silva, Cledir de A. Amaral, Oyatagan L. P. da Silva, Tiago B. do Nascimento, Alessandra L. P. de Oliveira, Eroína M. de Melo, Carlos Roberto T. Ferreira, Vitor G. F. da Costa, Sandro Victor A. Melo, Yves B. Feitoza e Mauro José de D. Moraes

Tabela 1: Definição e importância atribuída ao esporte

\begin{tabular}{|c|c|}
\hline Variáveis & n $(\%)$ \\
\hline \multicolumn{2}{|l|}{ Definição de esporte $(n=674)$} \\
\hline Conceitos relacionados ao esporte de rendimento & $332(49,2)$ \\
\hline Conceitos relacionados ao esporte educacional & $180(26,7)$ \\
\hline Conceitos relacionados ao esporte de participação & $399(59,2)$ \\
\hline \multicolumn{2}{|l|}{ Importância atribuída ao esporte $(n=674)$} \\
\hline Muito importante & $354(52,5)$ \\
\hline Importante & $269(39,9)$ \\
\hline Indiferente & $30(4,5)$ \\
\hline Pouco importante & $16(2,4)$ \\
\hline Nada Importante & $5(0,7)$ \\
\hline \multicolumn{2}{|l|}{ Importância do esporte para a saúde (n=672) } \\
\hline $\operatorname{Sim}$ & $625(93,0)$ \\
\hline Não & $4(0,6)$ \\
\hline Em parte & $41(6,1)$ \\
\hline Não sei & $2(0,3)$ \\
\hline \multicolumn{2}{|c|}{ Entende que o esporte ajuda no rendimento escolar $(n=668)$} \\
\hline Sim & $336(50,3)$ \\
\hline Não & $73(10,9)$ \\
\hline Em parte & $209(31,3$ \\
\hline Não sei & $50(7,5)$ \\
\hline \multicolumn{2}{|c|}{ Entende que o esporte pode ajudar a equilibrar o estresse diário $(n=669)$} \\
\hline Sim & $553(82,7)$ \\
\hline Não & $17(2,5)$ \\
\hline Em parte & $82(12,3)$ \\
\hline Não sei & $17(2,5)$ \\
\hline
\end{tabular}

Fonte: Dados da pesquisa (2020). 
Conhecimentos e Práticas de Esporte de Estudantes do Ensino Médio das Regionais do Estado do Acre Eliane Elicker, Adriane C. da Silva, Cledir de A. Amaral, Oyatagan L. P. da Silva, Tiago B. do Nascimento, Alessandra L. P. de Oliveira, Eroína M. de Melo, Carlos Roberto T. Ferreira, Vitor G. F. da Costa, Sandro Victor A. Melo, Yves B. Feitoza e Mauro José de D. Moraes

Na Tabela 2 estão expostos os resultados das questões relacionadas à prática de esporte, em que pode se observar que muitos estudantes não praticam esporte em seu tempo livre $(41,7 \%)$.

Os estudantes que referiram praticar esportes atualmente destacaram como os principais motivos a melhora do desempenho físico (57,5\%), por ser um hábito saudável para qualidade de vida e bem-estar $(21,2 \%)$ e para relaxar no tempo livre $(14,3 \%)$. Aqueles que não praticam esporte atualmente indicaram como motivos a falta de tempo ou por terem outras prioridades $(55,7 \%)$, a preguiça, o desinteresse ou a desmotivação $(24,4 \%)$ e a dificuldade de acesso e falta de espaços para a prática $(7,0 \%)$.

Tabela 2: Prática de esporte atual ou em algum momento da vida.

\begin{tabular}{|c|c|}
\hline Variáveis & n $(\%)$ \\
\hline \multicolumn{2}{|l|}{ Prática atual de algum esporte no seu tempo livre $(n=669)$} \\
\hline Sim & $389(58,3)$ \\
\hline Não & $280(41,7)$ \\
\hline \multicolumn{2}{|l|}{ Praticou algum esporte regularmente no passado $(n=272)$} \\
\hline Sim & $219(80,5)$ \\
\hline Não & $53(19,5)$ \\
\hline \multicolumn{2}{|l|}{ Motivos para praticar esportes* $(n=392)$} \\
\hline Melhoria do desempenho físico & $225(57,5)$ \\
\hline Hábito saudável para qualidade de vida e bem-estar & $83(21,2)$ \\
\hline Relaxar no tempo livre & $56(14,3$ \\
\hline Competição & $17(4,3)$ \\
\hline Relacionamentos/novas amizades & $10(7,0)$ \\
\hline Recomendação médica & $1(0,02)$ \\
\hline \multicolumn{2}{|l|}{ Modalidades mais praticadas $*(n=386)$} \\
\hline Futsal/futebol & $180(46,6)$ \\
\hline Voleibol/basquetebol/handebol & $127(32,9)$ \\
\hline Esportes individuais (natação/atletismo/tênis e outros) & $52(13,5)$ \\
\hline Outros & $27(7,0)$ \\
\hline
\end{tabular}

Motivos para não praticar esportes** $(\mathrm{n}=273)$

licere, Belo Horizonte, v.24, n.3, set/2021. 
Conhecimentos e Práticas de Esporte de Estudantes do Ensino Médio das Regionais do Estado do Acre Eliane Elicker, Adriane C. da Silva, Cledir de A. Amaral, Oyatagan L. P. da Silva, Tiago B. do Nascimento, Alessandra L. P. de Oliveira, Eroína M. de Melo, Carlos Roberto T. Ferreira, Vitor G. F. da Costa, Sandro Victor A. Melo, Yves B. Feitoza e Mauro José de D. Moraes

Falta de tempo/outras prioridades (estudo, trabalho, família e outros)

Preguiça/desinteresse/desmotivação

Dificuldade de acesso (horário, distância, outros)/falta de espaços

$19(7,0)$

Questões de saúde

Falta de orientação/estímulo

Não gosta da competição em si

Falta de companhia

Devido à idade

Questões econômicas (custos acima das condições)

Outros

$2(0,7)$

Fonte: Dados da pesquisa (2020).

*Poderia marcar mais de uma opção.

**Poderia marcar até 3 motivos.

Identificamos que grande parte dos alunos $(84,8 \%)$ frequentam as aulas de educação física, sendo a prática de esportes com regularidade nas aulas referida por $72 \%$ deles. Entre os alunos que têm frequência irregular ou não frequentam as aulas, os motivos principais foram a preguiça, o desinteresse ou a desmotivação, 54\%, e não gostar de educação física, 13,2\%. Também observamos que, entre os não praticantes de esportes nas aulas de educação física, a metade afirmou não gostar de esportes e outros $20 \%$ informaram que a escola não dispunha de um espaço adequado para tais práticas (Tabela 3).

Tabela 3: Frequência e prática de esporte nas aulas de Educação Física.

\begin{tabular}{lc}
\hline \multicolumn{1}{c}{ Variáveis } & n $(\boldsymbol{\%})$ \\
\hline Frequência nas aulas de Educação Física $(\mathrm{n}=664)$ & $565(85,1)$ \\
Regularmente & $93(14,0)$ \\
Às vezes & $6(0,9)$ \\
Não frequenta & $49(53,8)$ \\
Motivo para não frequentar regularmente as aulas $(\mathrm{n}=91)$ & $12(13,2)$ \\
Preguiça, desinteresse, desmotivação & \\
Não gosta da Educação Física & \\
\hline
\end{tabular}

Licere, Belo Horizonte, v.24, n.3, set/2021. 
Conhecimentos e Práticas de Esporte de Estudantes do Ensino Médio das Regionais do Estado do Acre Eliane Elicker, Adriane C. da Silva, Cledir de A. Amaral, Oyatagan L. P. da Silva, Tiago B. do Nascimento, Alessandra L. P. de Oliveira, Eroína M. de Melo, Carlos Roberto T. Ferreira, Vitor G. F. da Costa, Sandro Victor A. Melo, Yves B. Feitoza e Mauro José de D. Moraes

Dispensado por motivo de saúde/trabalho/curso

Outro

Prática de esportes nas aulas de Educação Física (n=656)

Regularmente

Às vezes

Não

Motivo de não praticar esportes nas aulas de Educação Física (n=20)

Não gosta de esportes

A escola não dispõe de espaço adequado

Outros

Fonte: Dados da pesquisa (2020).

\section{Discussão}

Considerando os dados apresentados, quanto ao local de residência, em que 81,6\% residem na área urbana, é importante registrar que a organização das cidades no Acre se estrutura de forma horizontal, sem a preocupação da união entre cidades, visto termos somente 22 municípios no estado. Esse aspecto é abordado no estudo de Santos e Peixinho (2015) sobre a conurbação, onde as cidades do Sul, Sudeste e algumas do Centro Oeste sofrem com essa união de duas ou mais cidades, em consequência do crescimento geográfico, situação distante da realidade do Acre.

Quanto à questão referente à cor da pele autodeclarada, não podemos deixar de destacar que $68,2 \%$ identificam-se com a cor parda e apenas $1,1 \%$ com a cor vermelha (indígena), situação que pode gerar certo estranhamento, visto que, o estado do Acre caracteriza-se, por uma extensa parcela de seu território, representado por áreas naturais, protegidas e compostas por Terras Indígenas (TIs) e Unidades de Conservação (UCs), com 16 Povos Indígenas identificados e outros Povos Indígenas recentemente identificados e em isolamento (ACRE, 2020).

Evidenciamos, ainda, que os registros dos primeiros movimentos migratórios no estado do Acre datam por volta de 1877 , com a chegada dos imigrantes nordestinos que 
Conhecimentos e Práticas de Esporte de Estudantes do Ensino Médio das Regionais do Estado do Acre Eliane Elicker, Adriane C. da Silva, Cledir de A. Amaral, Oyatagan L. P. da Silva, Tiago B. do Nascimento, Alessandra L. P. de Oliveira, Eroína M. de Melo, Carlos Roberto T. Ferreira, Vitor G. F. da Costa, Sandro Victor A. Melo, Yves B. Feitoza e Mauro José de D. Moraes

iniciaram a abertura de seringais, avançando pelas três vias hidrográficas existentes: o Rio Acre, o Alto-Purus e o Alto-Juruá (INSTITUTO BRASILEIRO DE GEOGRAFIA E ESTATÍSTICA, 2017). Dessa forma, entendemos a autodeclaração da cor da pele parda e não vermelha em função da miscigenação, mas alertamos para o preconceito racial existente em nossa sociedade, inviabilizando grupos sociais desfavorecidos, que atravessam a linguagem verbal e não verbal (SCHUCMAN, 2012; INSTITUTO BRASILEIRO DE GEOGRAFIA E ESTATÍSTICA, 2013).

Considerando o início da prática esportiva por volta dos 9 anos por ambos os sexos, destacamos que isso coincide com os anos iniciais do ensino fundamental, momento em que o estudante tem maiores oportunidades de experiências corporais individuais e coletivas, especialmente na Educação Física Escolar. Em contrapartida, sabemos que, na realidade do Acre, nos anos iniciais a disciplina de educação física se restringe a algumas práticas recreativas em que o fenômeno esportivo nesse nível de ensino é bastante incipiente. Estudos apontam para a existência de que as aulas de educação física, a depender do contexto, são ministradas/conduzidas pelo/a professor/a de referência da sala, identificado/a também como "unidocente" (BRASIL, 2010; CONTREIRA; KRUG, 2010; KRUG et al., 2019). Então, nessa fase inicial, a depender do local, é comum termos aulas regidas por pedagogos, o que inviabiliza as experiências corporais esportivas.

O Diagnóstico Nacional do Esporte, Atividade Física e Lazer (Diesporte) aponta que o início da prática esportiva ocorre entre 6 e 10 anos, e que meninos o fazem antes das meninas (BRASIL, 2015a). A idade para iniciação esportiva tem sido um assunto bastante polêmico, mas pouco explorado em todas as suas dimensões. Segundo estudo realizado por Silva; Fernandes e Celani (2001), na literatura especializada existe uma variabilidade nas indicações quanto à idade para o início da prática esportiva, 
Conhecimentos e Práticas de Esporte de Estudantes do Ensino Médio das Regionais do Estado do Acre

Eliane Elicker, Adriane C. da Silva, Cledir de A. Amaral, Oyatagan L. P. da Silva, Tiago B. do

Nascimento, Alessandra L. P. de Oliveira, Eroína M. de Melo, Carlos Roberto T. Ferreira, Vitor G. F. da Costa, Sandro Victor A. Melo, Yves B. Feitoza e Mauro José de D. Moraes

principalmente no que diz respeito às modalidades individuais, com média de 8,9 anos, e para as coletivas a média é de 11,7 anos.

No entanto, os autores salientam que as exigências de rendimento devem estar amparadas e adequadas aos níveis de desenvolvimento individuais. Orienta-se que haja uma predominância de indicações para o plano das capacidades coordenativas e condicionais, notadamente no que concerne ao desenvolvimento dessas capacidades, sem, no entanto, relacioná-las com as necessidades e exigências da prática concreta do esporte (SILVA; FERNANDES; CELANI, 2001).

Quanto ao entendimento do que é o esporte, a Lei nº 9.615 de 1998 inicialmente apresenta três diferentes dimensões para o esporte, a saber: desporto educacional; desporto de participação; desporto de rendimento (BRASIL, 1998).

A percepção de esporte pelos alunos dentro da perspectiva do esporte de participação, cujo objetivo não está na produção de algo, mas no próprio encontro entre os sujeitos. Essa forma de apropriação do bem cultural esporte visa à participação ativa e não seletiva, no que se refere ao acesso de candidatos a participantes (STIGGER, 2002).

Também identificamos que os entrevistados atribuem outro significado ao esporte, que remete ao conceito de esporte de rendimento. Esse tipo de esporte se desenvolveu e tomou uma proporção de esporte espetáculo, difundido através dos meios de comunicação e aceito mundialmente. No entanto, só está acessível a uma pequena parcela da população; aqueles com menor poder aquisitivo são meros espectadores e, ainda assim, através de alguns meios de comunicação como a televisão, pois esse tipo de esporte costuma ter alto custo e está distante da realidade concreta da maioria.

Sendo assim, observamos que a construção do conceito atribuído ao esporte pelos estudantes se dá essencialmente pelo que eles vivenciam e por aquilo que é 
Conhecimentos e Práticas de Esporte de Estudantes do Ensino Médio das Regionais do Estado do Acre

Eliane Elicker, Adriane C. da Silva, Cledir de A. Amaral, Oyatagan L. P. da Silva, Tiago B. do

Nascimento, Alessandra L. P. de Oliveira, Eroína M. de Melo, Carlos Roberto T. Ferreira, Vitor G. F. da Costa, Sandro Victor A. Melo, Yves B. Feitoza e Mauro José de D. Moraes

apresentado através dos meios midiáticos.

Uma reflexão necessária é sobre a baixa frequência do entendimento dos conceitos apresentados que remetem ao esporte educacional, o que evidencia potencial negligência na condução da disciplina Educação Física quanto à tematização do conteúdo esportes. Advoga-se que a tematização dos esportes nas aulas de Educação Física, especialmente no ensino médio, deve perpassar por estudos e reflexões sobre as vertentes do fenômeno esportivo e suas relações com a cultura e com as condições de uma sociedade desigual como a brasileira, de modo a contribuir com a formação de cidadãos conscientes e críticos de sua realidade no que tange às práticas esportivas.

Paradoxalmente, embora a maioria dos estudantes reconheçam a prática de esportes como muito importante e importante, destacando seu benefício para a saúde e equilíbrio do estresse, quase metade não é praticante atual e um quinto nunca praticou regularmente qualquer modalidade esportiva. Esses achados encontram ressonância no estudo Diesporte, que revelou que $74,4 \%$ dos brasileiros entre 15 e 74 anos não praticavam esportes, sendo destacado que tal índice se encontra dentro da média global (BRASIL, 2015b).

Foi também no Diesporte que identificamos semelhanças dos achados da presente pesquisa em relação à não prática atual/abandono dos esportes. Os alunos tinham média de idade de 16 anos, e o período apontado pelo Diesporte em que ocorre o abandono da prática esportiva em nível nacional está entre 16 e 24 anos, o qual sugere que o abandono está relacionado ao período em que os indivíduos saem da escola para o mundo do trabalho, mas destaca que são também as obrigações com os estudos, trabalho ou família os principais motivos para o abandono das práticas esportivas no País (BRASIL, 2015b). 
Conhecimentos e Práticas de Esporte de Estudantes do Ensino Médio das Regionais do Estado do Acre

Eliane Elicker, Adriane C. da Silva, Cledir de A. Amaral, Oyatagan L. P. da Silva, Tiago B. do

Nascimento, Alessandra L. P. de Oliveira, Eroína M. de Melo, Carlos Roberto T. Ferreira, Vitor G. F. da Costa, Sandro Victor A. Melo, Yves B. Feitoza e Mauro José de D. Moraes

A realidade dos estudantes do Acre reforça os dados nacionais mostrando a falta de tempo e outras prioridades como escola, trabalho e família como os principais motivos para a não realização de práticas esportivas, mas convém salientar a preguiça, o desinteresse ou a desmotivação, a dificuldade de acesso e falta de instalações esportivas como motivos frequentes.

Gaya et al. (1997) alertam que devemos considerar que para crianças de nível socioeconômico mais baixo a atribuição precoce de tarefas domésticas reduz de forma importante o tempo de lazer e definem, provavelmente, um perfil psicológico da mesma forma diferenciado entre o sexo.

Além desses fatores, a falta de condições objetivas e a necessidade de mobilidade urbana típicas do Brasil, também estão presentes no Acre, deixando escasso o tempo para a prática de esportes, visto o Estado organizar-se de forma horizontal os elementos espaciais de áreas não metropolitanas, desfavorecem a mobilidade de acesso aos equipamentos que possibilitam suas práticas (SANTOS; PEIXINHO, 2015).

De maneira similar aos resultados do presente estudo, a busca pelo bem-estar e melhoria da qualidade de vida também foram as razões apontadas pelos brasileiros tanto para praticar esportes quanto para atividades físicas em geral (BRASIL, 2015b).

Os motivos relacionados à prática do esporte são bastante diversificados. Registra-se que a existência de aspectos socioculturais e ambientais influenciam a escolha das práticas esportivas, e entre esses motivos está a diversão, o prazer pela prática e a amizade, além de competência técnica, competição, saúde e aptidão física, afiliação, reconhecimento social (BECKER JÚNIOR, 2000; BERNARDES; YAMAJI; GUEDES, 2015).

Os motivos para a prática do esporte estão alinhados ao posicionamento da Sociedade Brasileira de Medicina do Esporte, que preconiza que a saúde e a qualidade 
Conhecimentos e Práticas de Esporte de Estudantes do Ensino Médio das Regionais do Estado do Acre

Eliane Elicker, Adriane C. da Silva, Cledir de A. Amaral, Oyatagan L. P. da Silva, Tiago B. do

Nascimento, Alessandra L. P. de Oliveira, Eroína M. de Melo, Carlos Roberto T. Ferreira, Vitor G. F. da Costa, Sandro Victor A. Melo, Yves B. Feitoza e Mauro José de D. Moraes

de vida do homem podem ser preservadas e aprimoradas pela prática regular de atividade física. O documento aponta que o sedentarismo é condição indesejável e representa risco para a saúde. Registra, ainda, evidências de que os indivíduos fisicamente ativos tendem a apresentar menor incidência da maioria das doenças crônico-degenerativas, fato que pode ser explicado por inúmeros benefícios fisiológicos e psicológicos decorrentes da prática regular da atividade física, dentre estas pode-se destacar os esportes (LAZZOLI et.al, 1998).

Melo (2010) enfatiza que a prática esportiva saudável contribui ainda para regular o sono e diminuir a ansiedade, promove o aumento do gasto energético, maior coordenação motora, melhora da capacidade respiratória, diminuição do estresse e redução do risco de doenças (hipertensão, obesidade, diabetes).

Em se tratando das modalidades mais praticadas, tem sido sugerido que a variedade esportiva brasileira somente pode ser constatada em seus pormenores por pesquisas de sentido local, desde que a variedade sociocultural não demonstre ser o único fator de influência. No entanto, essa variabilidade parece não existir quando a modalidade é o futsal e o futebol, pois foram as modalidades mais citadas em todas as regiões do País no Diesporte (BRASIL, 2015b) e corroboradas no presente estudo, o qual mostra em conjunto as modalidades voleibol, basquete e handebol em segundo nível de preferência dos alunos.

Dessa forma, observamos uma predileção por esportes coletivos, o que reforça o aspecto da influência social, de estar com os amigos, fatores já referenciados por Stigger (2002), Bernardes; Yamaji e Guedes (2015) e Becker Júnior (2000). Além disso, algumas práticas individuais necessitam de uma estrutura mais adequada, como, por exemplo, a natação e o tênis; já as modalidades coletivas referenciadas pelos estudantes podem ser facilmente adaptadas ao número de participantes e ao local.

licere, Belo Horizonte, v.24, n.3, set/2021. 
Conhecimentos e Práticas de Esporte de Estudantes do Ensino Médio das Regionais do Estado do Acre

Eliane Elicker, Adriane C. da Silva, Cledir de A. Amaral, Oyatagan L. P. da Silva, Tiago B. do

Nascimento, Alessandra L. P. de Oliveira, Eroína M. de Melo, Carlos Roberto T. Ferreira, Vitor G. F. da Costa, Sandro Victor A. Melo, Yves B. Feitoza e Mauro José de D. Moraes

Estímulos para as práticas esportivas de crianças, adolescentes, jovens e adultos pelos professores de educação física na escola devem ser ressaltados e valorizados, já que estes são, em muitos casos, a única possibilidade concreta para tais práticas.

Chamou a atenção que dentre os estudantes respondentes, os que se referiram por frequentar as aulas irregularmente ou que não as frequentam, em sua maioria apontaram como motivos a preguiça, o desinteresse ou a desmotivação. Salienta-se que tais motivos não sãojustificáveis sob o ponto de vista pedagógico, uma vez que a Educação Física é um componente curricular obrigatório, portanto, suas ações não podem estar desvinculadas do Projeto Político Pedagógico da instituição de ensino (BRASIL, 1996; CESARO, 2016). Denota-se que a educação formal, em particular a Educação Física na educação básica, precisa se tornar atrativa, desafiadora, além de um espaço lúdico com oferta de instrumentais teóricos e práticos que subsidiem a construção do conhecimento e emancipação dos estudantes, e não um espaço e uma disciplina que apenas dedica-se à reprodução dos conteúdos, sem críticas e problematizações. Mas, sim, um espaço de visibilidade para as diferenças, que pese na educação física escolar o estudo, a partir das experiências e vivências individuais e coletivas com os esportes.

Desse modo, torna-se mister que esse componente curricular seja construído e desenvolvido com base na realidade, anseios e necessidades da comunidade escolar, aproximando-se dos interesses sociais para estimular a adoção de um estilo de vida ativo e saudável, visando reduzir o número de não praticantes e as consequências do sedentarismo, além de propiciar aprendizagens relativas à cultura corporal de movimento dentro de uma perspectiva crítica e emancipatória.

Por outro lado, cabe salientar que em geral as aulas de Educação Física, apesar do intenso calor acreano, ocorrem geralmente em espaços abertos, com cobertura 
Conhecimentos e Práticas de Esporte de Estudantes do Ensino Médio das Regionais do Estado do Acre

Eliane Elicker, Adriane C. da Silva, Cledir de A. Amaral, Oyatagan L. P. da Silva, Tiago B. do

Nascimento, Alessandra L. P. de Oliveira, Eroína M. de Melo, Carlos Roberto T. Ferreira, Vitor G. F. da Costa, Sandro Victor A. Melo, Yves B. Feitoza e Mauro José de D. Moraes

parcial e sem climatização. Tais aspectos podem vir a ser influenciadores na preguiça, desinteresse e desmotivação, citados pelos alunos e alunas deste estudo. já que o calor no norte do país é intenso.

Diante disso, podemos chamar a atenção para o estresse térmico, visto ser um dos fatores a afetar o desempenho humano em diversas atividades físicas e práticas esportivas, devendo ser levado em consideração para a melhoria das condições das práticas (RODRIGUES; ALMEIDA, 2009; REZENDE et al., 2019).

Salienta-se, ainda, outros fatores vinculados à ausência parcial ou total dos estudantes do ensino médio nas aulas de Educação Física. Esses estudantes justificam sua ausência devido ao comportamento sedentário, como assistir TV, jogos eletrônicos e o uso excessivo do computador e/ou celular, bem como devido às demandas relativas às atividades intelectuais (tarefas escolares, leitura, cursos de formação, trabalho), o que diminui significativamente a participação nas aulas de educação física, especialmente dos estudantes mais velhos que trabalham e que têm uma percepção negativa de saúde e cansaço excessivo no trabalho (SILVA et al., 2009).

Coadunamos, também, o fato de a adolescência representar um período de grandes transformações, surgimento de novas responsabilidades e aumento do convívio social. Nessa fase, os jovens podem passar a dar mais importância à opinião dos amigos e de seu grupo de socialização, ao invés de professores e pais, podendo também influenciar de modo positivo ou negativo na sua busca pela prática esportiva (MELO, 2010).

Todavia, salientamos que é no Ensino Médio que são necessários outros aprofundamentos em relação às temáticas da cultura corporal, de modo a possibilitar a construção de conhecimentos que tenham sentido e proximidade para o estudante, pois estes e nem os praticantes dos esportes coletivos não encontram, "“...] intencionalidade 
Conhecimentos e Práticas de Esporte de Estudantes do Ensino Médio das Regionais do Estado do Acre

Eliane Elicker, Adriane C. da Silva, Cledir de A. Amaral, Oyatagan L. P. da Silva, Tiago B. do

Nascimento, Alessandra L. P. de Oliveira, Eroína M. de Melo, Carlos Roberto T. Ferreira, Vitor G. F. da Costa, Sandro Victor A. Melo, Yves B. Feitoza e Mauro José de D. Moraes

pedagógica, uma organização dos conteúdos e das sequências de aprendizagem de forma a permitir uma apropriação dos saberes pertencentes à Educação Física" em suas práticas (CESARO, 2016, p. 87).

A realização da presente pesquisa com estudantes exclusivamente das instituições federais no Acre - Colégio de Aplicação da Ufac e o Instituto Federal do Acre —, não permitem fazer inferências para os estudantes de nível médio em geral, uma vez que há, nos municípios-sede das regionais do estado, escolas de ensino médio da rede estadual e, eventualmente, da rede privada, o que representa uma limitação do estudo.

Convém salientar, porém, que tal escolha se deu devido a limitações orçamentárias e de recursos para a realização da presente pesquisa. Contudo, a limitação apresentada pode ser minimizada, pois se trata de estudantes de instituições públicas, dentre elas o Ifac, que possui uma política de cotas para ingresso que visa garantir maior diversidade possível de seus estudantes, representando, via de regra, todos os estratos sociais de cada comunidade.

\section{Considerações Finais}

Considerando que o objetivo foi descrever os conhecimentos e práticas de esporte de estudantes do ensino médio das regionais do estado do Acre, cabe ressaltar que a prática esportiva se inicia independente do sexo, por volta dos 9 anos, tendo o futsal e o futebol como os principais esportes praticados. Embora seja reconhecida a importância geral das práticas de esportes, em particular para aspectos relacionados à saúde e à qualidade de vida, boa parte dos estudantes não são praticantes atuais, tendo como principais justificativas a falta de tempo e o compromisso com estudos, família e trabalho.

licere, Belo Horizonte, v.24, n.3, set/2021. 
Conhecimentos e Práticas de Esporte de Estudantes do Ensino Médio das Regionais do Estado do Acre

Eliane Elicker, Adriane C. da Silva, Cledir de A. Amaral, Oyatagan L. P. da Silva, Tiago B. do

Nascimento, Alessandra L. P. de Oliveira, Eroína M. de Melo, Carlos Roberto T. Ferreira, Vitor G. F. da Costa, Sandro Victor A. Melo, Yves B. Feitoza e Mauro José de D. Moraes

O entendimento dos estudantes do fenômeno esportivo está fortemente atrelado aos conceitos que se relacionam ao esporte de participação e ao esporte de rendimento, sendo pouco frequente a compreensão do esporte em sua dimensão vinculada ao esporte educacional.

Depreende-se o entendimento que os estudantes têm do esporte identificando-o de duas formas, como uma prática de participação voluntária, que está em consonância com a sua realidade e vivência; e enquanto um fenômeno possuidor de regras fixas, onde se busca alcançar resultados por meio da performance, amplamente divulgado na grande mídia.

Além dos fatores culturais e a influência da mídia na preferência dos esportes, neste caso do futsal e futebol, observa-se que estão presentes, além da coletividade e interação social, um outro aspecto que favorece à sua prática é a facilidade de adaptação das regras ao espaço e ao número de participantes, muito buscada pelas crianças e adolescentes.

A Educação Física Escolar é o espaço privilegiado para garantir o direito da prática esportiva aos alunos, contudo, não se pode negar a necessidade de que tais práticas devam ser orientadas por propostas pedagógicas que permitam a construção crítica e emancipatória de conceitos e vivências práticas não negligenciando a necessária reflexão sobre temas que tratam da problematização e visibilização de grupos minoritários, apontando distintos pontos de vistas sobre as diferentes manifestações da cultura corporal de movimento.

Neste sentido, o presente estudo aponta para a necessidade de criação de Políticas Públicas focadas na ampliação e na apropriação do esporte no contexto educacional e de participação popular como forma de garantia do direito social, 
possibilitando aos estudantes e a população em geral o desenvolvimento de uma cultura esportiva dentro de uma perspectiva crítica.

\section{REFERÊNCIAS}

ACRE. COMISSÃO PRÓ-ÍNDIO DO ACRE (CPI-ACRE). Povos Indígenas no Acre. Rio Branco: 2020. Disponível em: https://cpiacre.org.br/povos-indigenas-no-acre/\#. Acesso em: 29 out. 2020.

ATHAYDE, P. et al. O esporte como direito de cidadania. Pensar a Prática, Goiânia,v. 19, n. 2, p. 490-501, abr/jun. 2016. Disponível em: http://www.revistas.ufg.br/fef/article/view/34049. Acesso em: 10 set. 2018.

BARBANTI, V. Dicionário de educação física e esporte. 3. ed. rev. ampl. Barueri: Brasil: Manole, 2011.

BECKER JÚNIOR, B. Manual de psicologia do esporte \& exercício. Porto Alegre: Nova Prova, 2000.

BERNARDES, A. G; YAMAJI, B. H. S; GUEDES D. P. Motricidade, v. 11, n. 2, p. 163-173, 2015. Disponível em: https://www.scielo.mec.pt/pdf/mot/v11n2/v11n2a16.pdf. Acesso em: 06 out. 2020.

BRASIL. Lei de Diretrizes e Bases da Educação Nacional. Lei no 9.394/1996, de 20 de dezembro de 1996. Estabelece as diretrizes e bases da educação nacional em 2019. Disponível em: http://www.planalto.gov.br/ccivil_03/Leis/L9394.htm. Acesso em: 17 set. 2020.

. Câmara dos Deputados. Lei n⿳ 9.615, de 24 de março de 1998. Institui normas gerais sobre desporto e dá outras providências. Disponível em: https://www2.camara.leg.br/legin/fed/lei/1998/lei-9615-24-marco-1998-351240publicacaooriginal-1-pl.html. Acesso em: 30 out. 2019.

Ministério da Educação, Conselho Nacional de Educação. Parecer n. 11, de 7 de julho de 2010. Diretrizes Curriculares Nacionais para o Ensino Fundamental de 9 (nove) anos. Disponível em: http://portal.mec.gov.br/dmdocuments/rceb007_10.pdf. Acesso em: 24 nov. 2020.

\begin{tabular}{ccccc} 
& Ministério do Esporte. Centros de Desenvolvimento de Esporte Recreativo e \\
\hline Lazer & - & REDE & CEDES. & 2015a.
\end{tabular} http://arquivo.esporte.gov.br/index.php/institucional/esporte-educacao-lazer-e-inclusaosocial/rede-cedes. Acesso em: 20 nov. 2015.

Ministério do Esporte. Diagnóstico Nacional do Esporte- DIESPORTE.

Caderno 1. Ministério dos Esportes, jun. 2015b. Disponível em: https://cev.org.br/arquivo/biblioteca/4029772.pdf. Acesso em: 18 set. 2020.

CARLAN, P.; KUNZ, E.; FENSTERSEIFER, P. E. O esporte como conteúdo da 
Educação Física escolar: estudo de caso de uma prática pedagógica "inovadora". Movimento, Porto Alegre, v. 18, n. 4, p. 55-75, out./dez. 2012. Disponível em: http://seer.ufrgs.br/Movimento/article/viewFile/29643/23448. Acesso em: 13 nov. 2020.

CESARO, H. L. de. Abandono discente nas aulas de educação física do ensino médio: uma etnografia escolar na rede estadual do meio-oeste catarinense. 2016. 135 f. Tese (Doutorado em Ciência do Movimento Humano)-Programa de PósGraduação em Ciências do Movimento Humano da Escola de Educação Física, Fisioterapia e Dança da Universidade Federal do Rio Grande do Sul. Porto Alegre, 2016. Disponível em: http://lume.ufrgs.br/handle/10183/15912. Acesso em: 30 out. 2020.

CONTREIRA, C.; KRUG, H. N. Educação Física nas séries iniciais do ensino fundamental: um estudo de caso com professores unidocentes. Lecturas: Educación Física y Deportes, Revista Digital, v. 15, n. 150, 2010. Disponível em: https://www.efdeportes.com/efd150/educacao-fisica-com-professores-unidocentes.htm. Acesso em: 24 nov. 2020.

EUZÉBIO, C. A.; ORTIGARA, V. Na teoria a prática é outral? Análise do conhecimento esportivo nos cursos de formação inicial de professores de educação física no sul catarinense. Rev. Bras. Ciênc. Esporte, Florianópolis, v. 33, n. 3, p. 653669, jul./set. 2011. Disponível em: http://www.scielo.br/scielo.php?pid=S010132892011000300009\&script=sci_abstract\&tlng=pt. Acesso em: 13 nov. 2020.

GAYA, A. C. A. et al.Crescimento e desempenho motor em escolares de 7 a 15 anos provenientes de famílias de baixa renda. Movimento.Porto Alegre, v. 4, n. 6, p. 1-24, 1997. Disponível em: http://seer.ufrgs.br/Movimento/article/view/13342/7615. Acesso em: 10 ago. 2020.

INSTITUTO BRASILEIRO DE GEOGRAFIA E ESTATÍSTICA (IBGE). Histórias e Fotos. Acre, 2017. Disponível em: http://cidades.ibge.gov.br/brasil/ac/historico. Acesso em: 29 out. 2020.

Estudos e análises - Informações Demográficas e Socioeconômicas, n. 2: Características étnico-raciais da população: classificação e identidades. Rio de Janeiro: 2013. Disponível em: http://biblioteca.ibge.gov.br/visualizacao/livros/liv63405.pdf. Acesso em: 29 out. 2020.

KRUG, H. N. et al. As dificuldades da prática pedagógica da educação física na unidocência. Pedagogia em Ação, Belo Horizonte, v. 12, n. 2, 2019. Disponível em: http://seer.pucminas.br/index.php/pedagogiacao/article/view/22121/16189. Acesso em: 24 nov. 2020.

LAZZOLI, J. K. et al.Sociedade Brasileira de Medicina do Esporte Posicionamento Oficial: Atividade física e saúde na infância e adolescência. Rev. Bras. Med. Esporte, Niterói, RJ. v. 4, n. 4, p. 107-109, jul./ago. 1998. Disponível em: http://www.scielo.br/scielo.php?pid=s1517-86921998000400002\&script=sci_arttext. Acesso em: 06 out. 2020.

MARCELlinO, N. C. Introdução aos estudos do lazer. Campinas: Autores Associados, 1996. 
MELO, N. B. C. de. Motivação de adolescentes para a prática esportiva. 2010. 38f. Trabalho de Conclusão (Graduação) - Escola de Educação Física da Universidade Federal de Minas Gerais, Minas Gerais, 2010.

PINTOS, A. E. et al. O direito ao esporte e ao lazer no contexto da política nacional do esporte. Revista Brasileira de Estudos do Lazer, Belo Horizonte.v. 3, n. 1, p. 38-52, jan./abr. $2016 . \quad$ Disponível em: http://periodicos.ufmg.br/index.php/rbel/article/view/508. Acesso em: 14 nov. 2018.

RAMOS, R.; ISAYAMA, H. F. Lazer e esporte: olhar dos professores de disciplinas esportivas do curso de educação física. Rev. bras. Educ. Fís. Esporte, São Paulo, v. 23, n. 4, p. 379-91, out./dez. 2009. Disponível em: http://www.scielo.br/scielo.php?pid=S180755092009000400007\&script=sci_abstract\&tlng=pt. Acesso em: 13 nov. 2020.

REZENDE, L. M. T. et al. Estresse térmico ambiental e termorregulacão em jogadores de futebol: uma revisão sistemática. Revista Brasileira de Ciências do Esporte, v. 41, n. 1, p. 10-25; 2019. Disponível em: http://www.scielo.br/pdf/rbce/v41n1/0101-3289rbce-41-01-0010.pdf. Acesso em: 29 out. 2020.

RODRIGUES, V. M.; ALMEIDA, R. M. Avaliação do Estresse Térmico e Risco de Hipertermia durante aulas de Educação Física do IFMT - Campus Cuiabá: Resultados Preliminares. Revista Profiscientia, n. 4, p. 93-108, 2009. Disponível em: https://www.profiscientia.ifmt.edu.br/profiscientia/index.php/profiscientia/article/view/ 37. Acesso em: 29 out. 2020.

SANTOS, A. E.; PEIXINHO, D. M. Processo de conurbação: elementos espaciais do fenômeno em área não metropolitana. Estudos Geográficos: Revista Eletrônica de Geografia, Rio Claro, v. 13, n. 1, p. 35-52, jan./jul. 2015. Disponível em: https://www.periodicos.rc.biblioteca.unesp.br/index.php/estgeo/article/view/10090/6932 . Acesso em: 29 out. 2020.

SCHUCMAN, L. V. Entre o "encardido", o "branco" e o "branquíssimo": Raça, hierarquia e poder na construção da branquitude paulistana. Tese (Doutorado) Programa de Pós-Graduação em Psicologia. Área de Concentração: Psicologia Social, Instituto de Psicologia da Universidade de São Paulo, 2012. Disponível em: https://www.ammapsique.org.br/baixe/encardido-branco-branquissimo.pdf. Acesso em: 29 out. 2020.

SILVA, K. S. da et al. Fatores associados à atividade física, comportamento sedentário e participação na Educação Física em estudantes do Ensino Médio em Santa Catarina, Brasil. Cad. Saúde Pública, Rio de Janeiro. v 25, n 10, p. 2187-2200, out, 2009. Disponível em: http://www.scielo.br/pdf/csp/v25n10/10.pdf. Acesso em: 10 set. 2020.

SILVA, F.M.; FERNANDES, L.; CELANI, F. O. Desporto de crianças e jovens: um estudo sobre as idades de iniciação. Revista Portuguesa de Ciências do Desporto,v. 1, n. 2, p. 45-55, 2001. Disponível em: http://rpcd.fade.up.pt/_arquivo/artigos_soltos/vol.1_nr.2/06.pdf. Acesso em: 06 out. 2020.

SOARES, J. M. O Programa esporte e lazer da cidade nos planos plurianuais do 
Governo Federal. Licere, v. 20, n. 3, p. 102-138, set. 2017. Disponível em: http://periodicos.ufmg.br/index.php/licere/article/view/1687. Acesso em: 20 set. 2019.

STIGGER, M. P. Esporte, lazer e estilos de vida: um estudo etnográfico. Campinas: Autores Associados, 2002.

TUBINO, M. J. G. Estudos brasileiros sobre o esporte: ênfase no esporte-educação. Maringá: Eduem, 2010.

\section{Endereço dos(as) Autores(as):}

Eliane Elicker

Endereço Eletrônico: elielicker@gmail.com

Adriane Corrêa da Silva

Endereço Eletrônico: adriane.acs@gmail.com

Cledir de Araújo Amaral

Endereço Eletrônico: cledir.amaral@ifac.edu.br

Oyatagan Levy Pimenta da Silva

Endereço Eletrônico: oyataganlevy@gmail.com

Tiago Barbosa do Nascimento

Endereço Eletrônico: ogaiti@gmail.com

Alessandra Lima Peres de Oliveira

Endereço Eletrônico: alessan.jp@gmail.com

Eroína Moreira de Melo

Endereço Eletrônico: eroinamello@gmail.com

Carlos Roberto Teixeira Ferreira

Endereço Eletrônico: carlostferreira@yahoo.com.br

Vitor Gomes Felisberto da Costa

Endereço Eletrônico: vitorfelisbertofelisberto@gmail.com

Sandro Victor Alves Melo

Endereço Eletrônico: sandro@ufac.br

Yves Benevides Feitoza

Endereço Eletrônico: yvesfeitoza@gmail.com

Mauro José de Deus Moraes

Endereço Eletrônico: maurodedeus@ outlook.com 